Supplement of Hydrol. Earth Syst. Sci., 25, 885-900, 2021

https://doi.org/10.5194/hess-25-885-2021-supplement

(c) Author(s) 2021. This work is distributed under

the Creative Commons Attribution 4.0 License.

(c) (i)

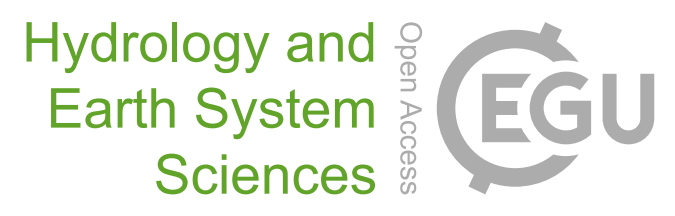

Supplement of

\title{
Assessing different imaging velocimetry techniques to measure shallow runoff velocities during rain events using an urban drainage physical model
}

Juan Naves et al.

Correspondence to: Juan Naves (juan.naves@udc.es)

The copyright of individual parts of the supplement might differ from the CC BY 4.0 License. 


\section{S1. Complementary results for the sensitivity analysis}

$30 \mathrm{~mm} \mathrm{~h}^{-1}$-rain-intensity experiments

-1- Pre-processing parameter $\left(X_{\text {ref_LSPIV }}=25 \%, X_{\text {ref_LSPIVb }}=0.25, X_{\text {ref_LSPIVu }}=15 \%, X_{\text {ref_BIV }}=0.6\right)$

- - IA size $\left(\mathrm{X}_{\mathrm{ref}}=32 \mathrm{px}\right)$

- $\operatorname{FAR}\left(\mathrm{X}_{\mathrm{ref}}=25 \mathrm{~Hz}\right)$
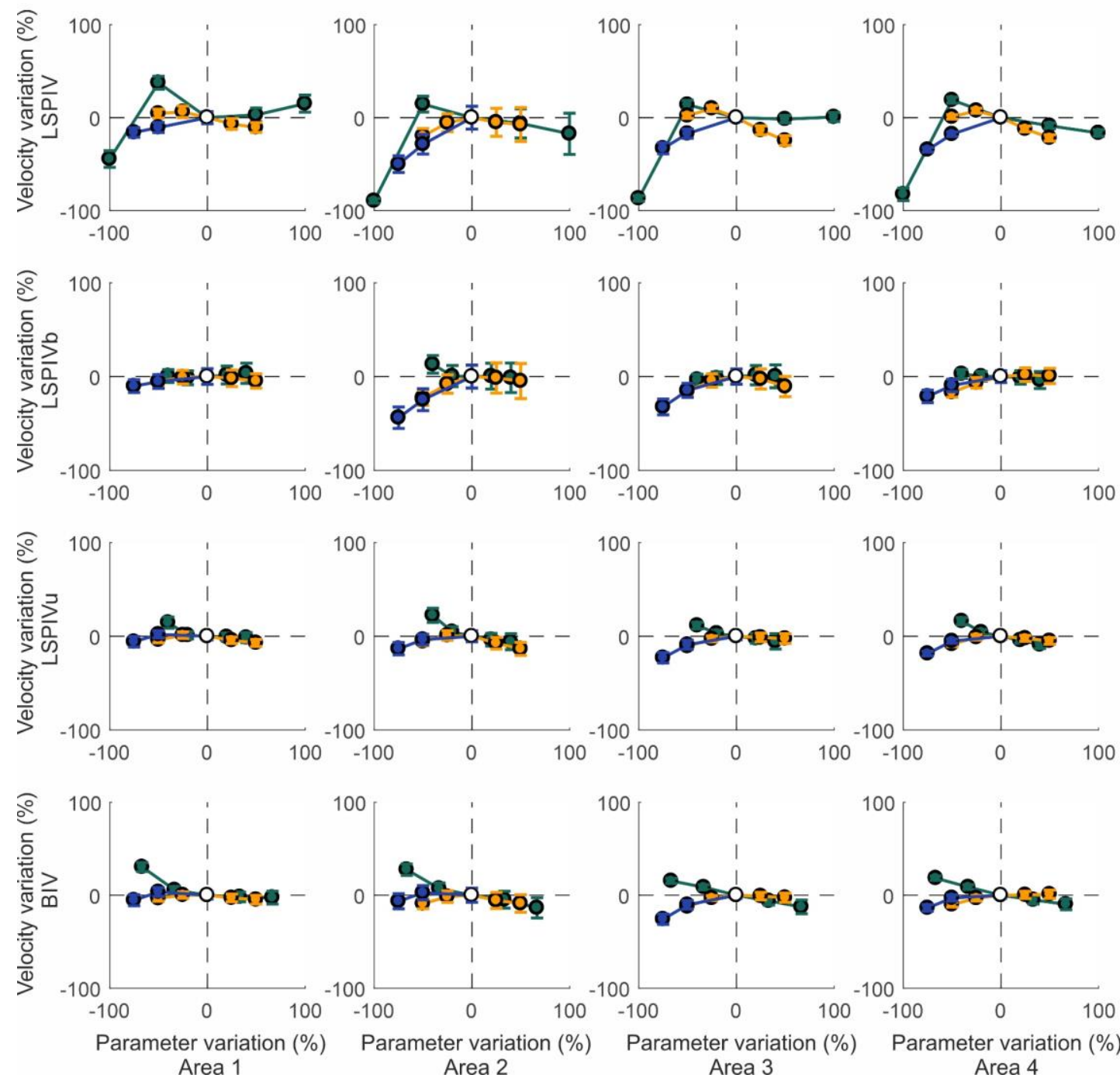

Figure S1: Percentage of variation in the mean velocities when varying parameters of the analysis for the four studied areas (columns) and the four imaging velocimetry techniques considered (rows) in the case of $30 \mathrm{~mm} \mathrm{~h}^{-}$ ${ }^{1}$ rainfall. Mean velocity variability for the different pairs of frames analyzed are included using whiskers. 


\section{$80 \mathrm{~mm} \mathrm{~h}^{-1}$-rain-intensity experiments}

- - Pre-processing parameter $\left(X_{\text {ref_LSPIV }}=25 \%, X_{\text {ref_LSPIVb }}=0.25, X_{\text {ref_LSPIVU }}=15 \%, X_{\text {ref_BIV }}=0.6\right)$

- - IA size $\left(\mathrm{X}_{\mathrm{ref}}=32 \mathrm{px}\right)$

$\rightarrow \quad \operatorname{FAR}\left(\mathrm{X}_{\mathrm{ref}}=25 \mathrm{~Hz}\right)$
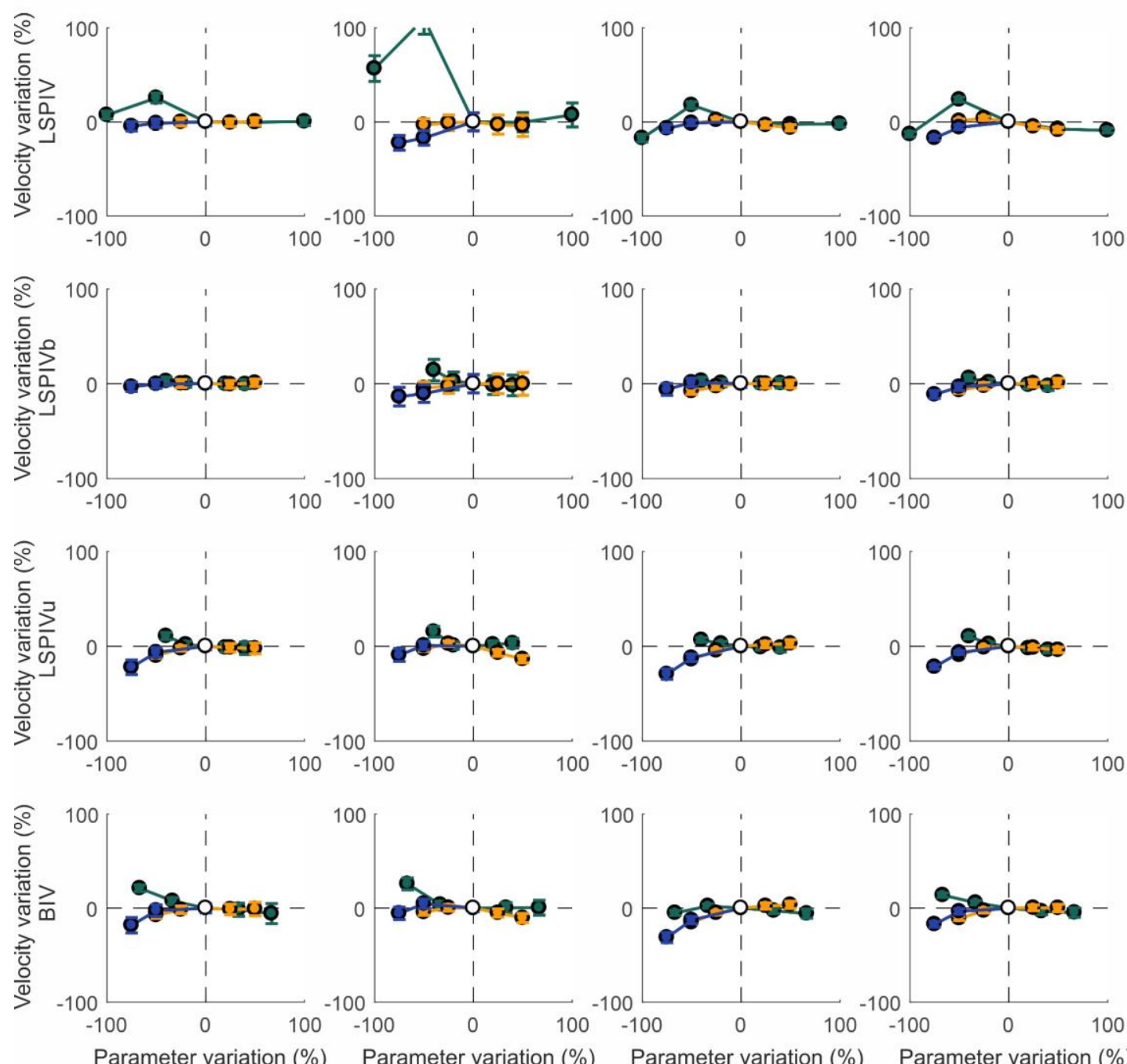
Area 1 Area 2 Area 3 Area 4

Figure S2: Percentage of variation in the mean velocities when varying parameters of the analysis for the four studied areas (columns) and the four imaging velocimetry techniques considered (rows) in the case of $80 \mathrm{~mm} \mathrm{~h}^{-}$ ${ }^{1}$ rainfall. Mean velocity variability for the different pairs of frames analyzed are included using whiskers. 


\section{S2. Complementary results for the velocity results comparison}

Velocity comparison Area 3

$\underline{30 \mathrm{~mm} \mathrm{~h}^{-1}}$

LSPIV

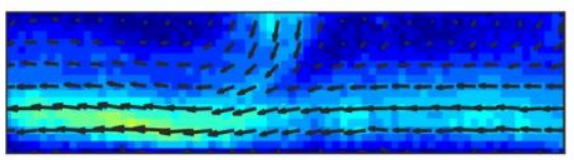

LSPIVb

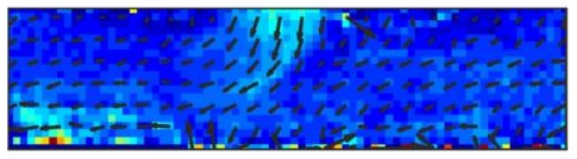

LSPIVu

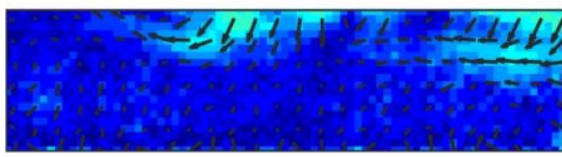

BIV

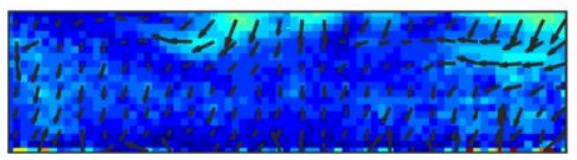

Velocity $(\mathrm{m} / \mathrm{s})$ :

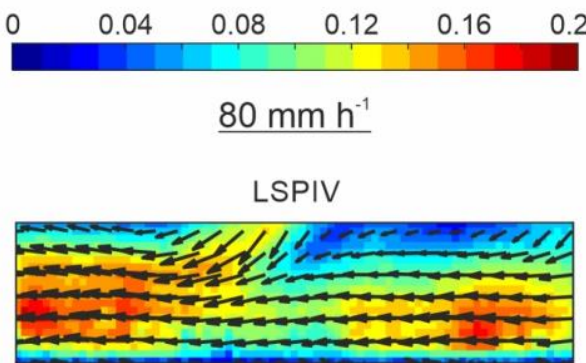

LSPIVb

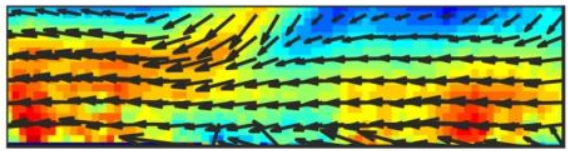

LSPIVU

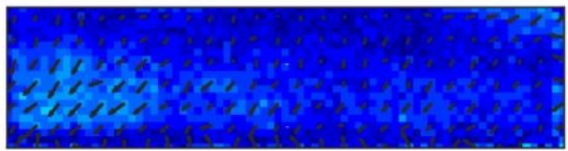

BIV

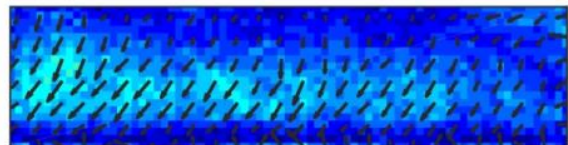

Figure S3: Velocity fields obtained for the cases of $30 \mathrm{~mm} \mathrm{~h}^{-1}$ and $80 \mathrm{~mm} \mathrm{~h}^{-1}$ in Area 3 .

Velocity $(\mathrm{m} / \mathrm{s})$

$\begin{array}{lllllll}\text { Velocity comparison Area 4 } & 0 & 0.04 & 0.08, & 0.12 & 0.16 & 0.20\end{array}$

$\underline{30 \mathrm{~mm} \mathrm{~h}^{-1}}$

LSPIV

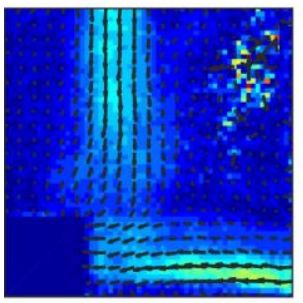

LSPIVU

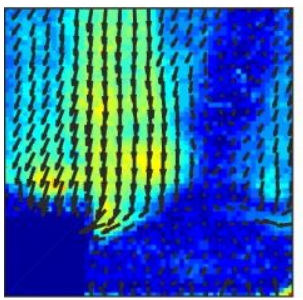

LSPIVb

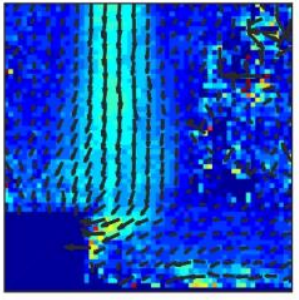

BIV

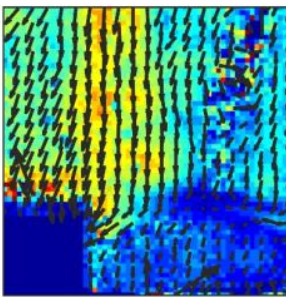

$80 \mathrm{~mm} \mathrm{~h}^{-1}$

LSPIV

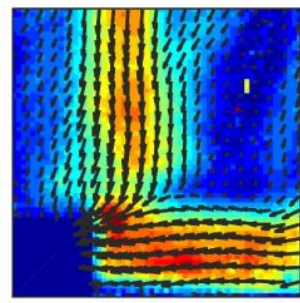

LSPIVU

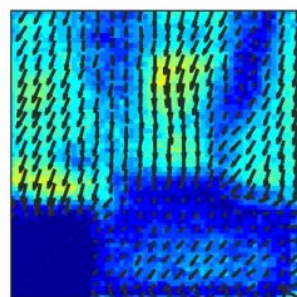

LSPIVb

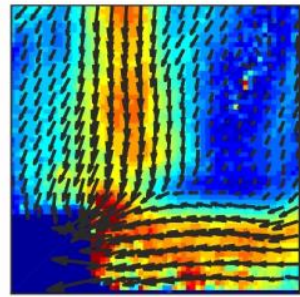

BIV

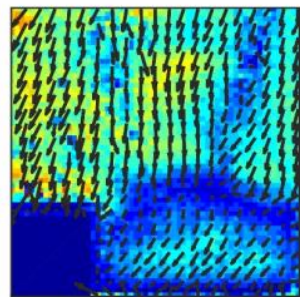

Figure S4: Velocity fields obtained for the cases of $30 \mathrm{~mm} \mathrm{~h}^{-1}$ and $80 \mathrm{~mm} \mathrm{~h}^{-1}$ in Area 4. 


\section{S3. Complementary results for the convergence study}

Convergence study: mean velocities (rain intensity $=30 \mathrm{~mm} \mathrm{~h}^{-1}$ )
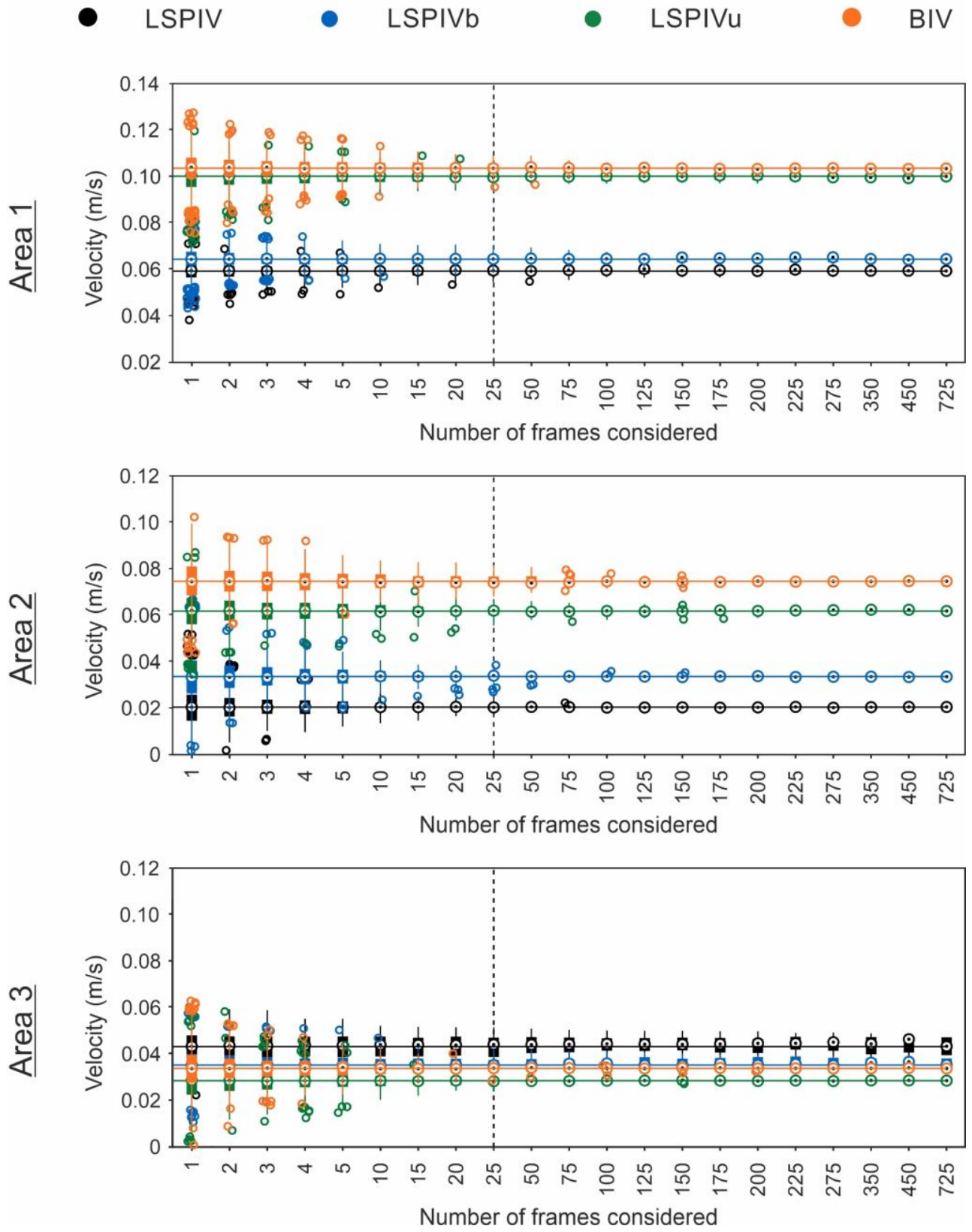

Figure S5: Mean velocity convergence study for rain intensity of $30 \mathrm{~mm} \mathrm{~h}^{-1}$ and Areas 1, 2, and 3. The horizontal line represents the mean velocity considering all the frames available (1500) for LSPIV (black), LSPIVb (blue), LSPIVu (green) and BIV (orange) techniques. Then, the variability in the mean velocity when the frames are divided into groups of different numbers of frames was represented by boxplots. 
Convergence study: mean velocities (rain intensity $=80 \mathrm{~mm} \mathrm{~h}^{-1}$ )

- LSPIV LSPIVb LSPIVu
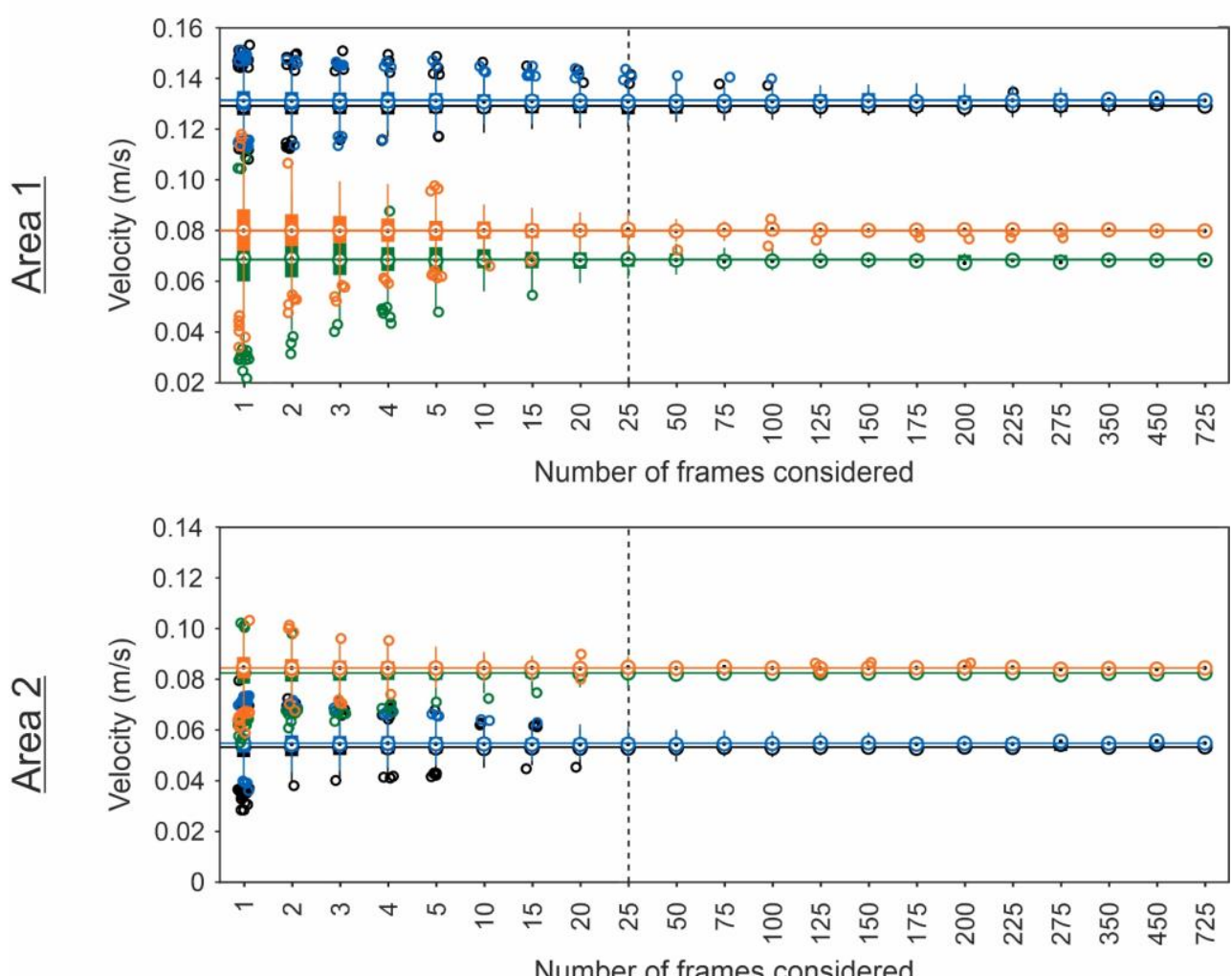

Number of frames considered

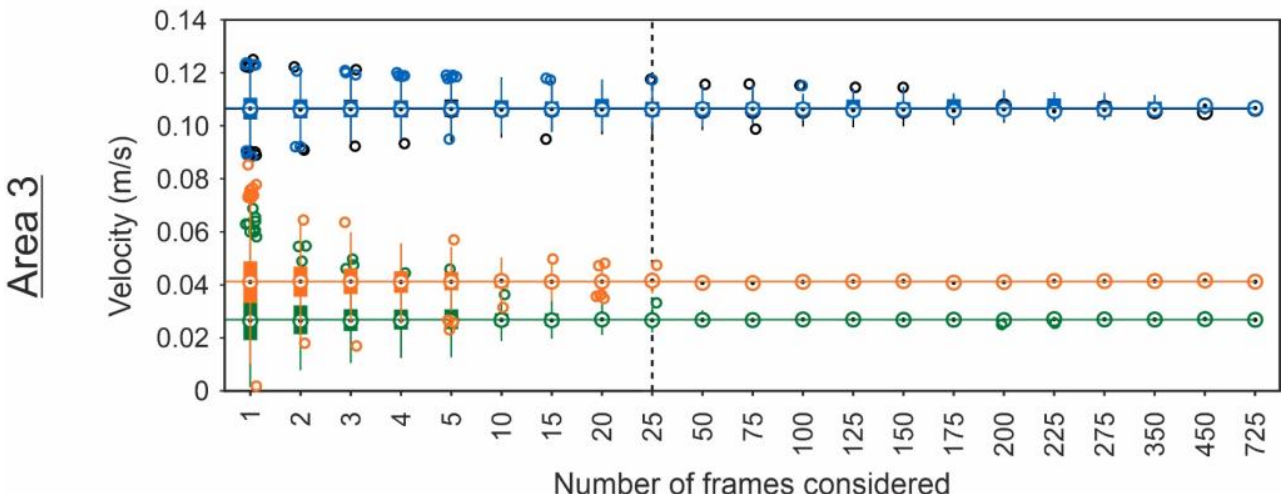

Figure S6: Mean velocity convergence study for rain intensity of $80 \mathrm{~mm} \mathrm{~h}^{-1}$ and Areas 1, 2, and 3. The horizontal line represents the mean velocity considering all the frames available (1500) for LSPIV (black), LSPIVb (blue), LSPIVu (green) and BIV (orange) techniques. Then, the variability in the mean velocity when the frames are divided into groups of different numbers of frames was represented by boxplots. 
Convergence study: mean velocities (Area 4)

- LSPIV $\quad$ LSPIVb
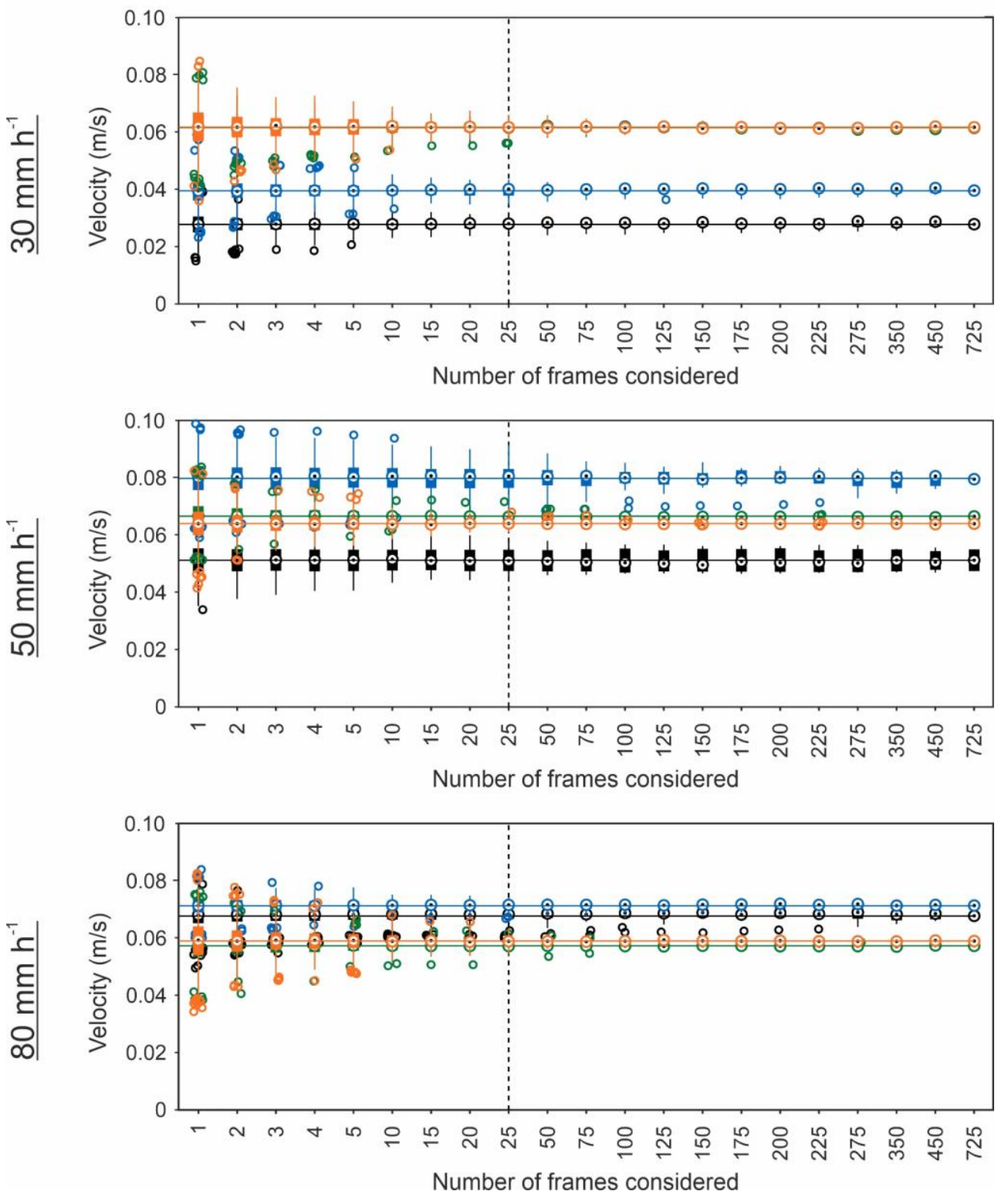

Figure S7. Mean velocity convergence study for Area 4 and rain intensities of 30, 50 and $80 \mathrm{~mm} \mathrm{~h}^{-1}$. The horizontal line represents the mean velocity considering all the frames available (1500) for LSPIV (black), LSPIVb (blue), LSPIVu (green) and BIV (orange) techniques. Then, the variability in the mean velocity when the frames are divided into groups of different numbers of frames was represented by boxplots. 